\title{
Los dominicos de primera hora y su contribución a la sistematización pedagógica medieval: la figura clave de Vicente de Beauvais (1190-1264)
}

\author{
The dominicans of first hour and their contribution \\ to medieval pedagogical systematization: the key \\ figure of Vincent de Beauvais (1190-1264)
}

\section{Javier VERGARA CIORDIA}

\author{
Departamento de Historia de la Educación. \\ Universidad Nacional de Educación a Distancia (UNED) \\ https://orcid.org/0000-0002-6118-5905 \\ fvergara@edu.uned.es
}

\begin{abstract}
This study analyzes the contribution of the first Dominicans to medieval pedagogy, through the pedagogical work of Vicente de Beauvais. His pedagogical works, although they are wide and very varied, focus on four core themes: history as a method of knowledge, the ideal of wisdom, the figures of the teacher and the disciple, and health education. Topics that served to turn pedagogy into a science, mark the pedagogy of the thirteenth century and serve as a bridge between classical pedagogy and humanist education. The research is supported by the study of four key pedagogical works: Libellus apologeticus, Speculum naturale, Speculum doctrinale and De eruditione filiorum nobilium.
\end{abstract}

Keywords: Order of Preachers; Vincent de Beauvais; Education; Wisdom; teacher; disciple; health education.
Resumen: El presente estudio analiza la aportación de los primeros dominicos a la educación medieval, a través de la obra pedagógica de Vicente de Beauvais. Sus trabajos pedagógicos, aunque son amplios y variados, se centraron en cuatro temas nucleares: la historia como método de conocimiento, el ideal de sabiduría, las figuras del maestro y del discípulo, y la educación para la salud. Temas que sirvieron para convertir la pedagogía en una ciencia, marcar la educación del siglo XIII y servir de puente entre la pedagogía clásica y la educación humanista. La investigación resume las tesis de sus cuatro obras pedagógicas clave: Libellus apologeticus, Speculum naturale, Speculum doctrinale y De eruditione filiorum nobilium.

Palabras clave: Orden de Predicadores; Vicente de Beauvais; Educación; Sabiduría; maestro; discípulo; educación para la salud. 


\section{NECESIDAD DE UN ESTUDIO}

Como es sabido, la Orden de Predicadores, fundada por Domingo de Guzmán y de Aza y confirmada por el papa Honorio III en 1216, es uno de los acontecimientos eclesiales más importantes de la Baja Edad Media. Nació para capitanear, junto con los franciscanos, el impulso de renovación pastoral y teológica que demandaba la inquieta sociedad del siglo XIII. El dominico de esta época no es un monje encerrado en el claustro monacal, no se vincula a zonas rurales ni a economías feudales. Es un mendicante secular que elige la ciudad como centro de actividad religiosa y pastoral. Un fraile que hace de la comunicación y la cultura las bases insoslayables de su carisma, que se desvive por el saber y el conocimiento, y que se le encuentra formándose en las principales universidades y centros de saber ${ }^{1}$. El propio Honorio III, con motivo de la confirmación de la Orden, llamó a los dominicos lumbreras de la verdad. Apelativo que no se reducía al solo anuncio de la fe, se trataba de mostrarla, enseñarla y vivirla. Un desiderátum de considerable magnitud pedagógica, que confirió a la Orden un carácter educativo indeleble, no suficientemente conocido, y al que la historiografía le debe una más que sentida reparación.

Esta dimensión educativa no es solo consecuencia práctica de su condición teológica. Es fruto de una sistemática pedagógica de calado que convirtió a los hijos espirituales de santo Domingo en uno de los pilares más emblemáticos de la pedagogía bajomedieval. Los primeros dominicos fueron los artífices de dar entidad científica a la educación, de convertir la pedagogía en ciencia. Es cierto que filósofos anteriores de la talla de Juan de Salisbury, Bernardo de Claraval, Pedro Lombardo, los victorinos Hugo y Ricardo de San Víctor, el Pseudo-Boecio y un largo elenco de autores había escrito sobre educación. Pero ninguno trató su estructura noética con tanta amplitud y sistematicidad como lo hicieron los primeros predicadores.

Una responsabilidad que recayó sobremanera en la persona y en la obra de Vicente de Beauvais (1190-1264). Fraile dominico de primera hora, que conoció en vida a Domingo de Guzmán, que convivió con él en París y que escribió las primeras obras educativas de la Orden, imprimiéndole una sistemática y un modo de pensar pedagógicos que habrían de marcar el devenir de la educación posterior. Cuatro grandes temas, tratados con amplitud y sistematicidad, definirían esa impronta: la tradición histórica como anclaje y validación de las ideas; la actualización de la sabiduría como síntesis de conocimiento, virtud y fe; los elementos

1 Cfr. Bonifacio Palacios MarTín, Los dominicos y las órdenes mendicantes en el siglo XIII», en VI Semana de Estudios Medievales, Instituto de Estudios Riojanos, Logroño, 1996, pp. 29-41. 
personales de la educación, sintetizados en la figura del maestro y del discípulo; y la educación para la salud en las distintas etapas de la vida. Temas que convertirán a los primeros dominicos y a Vicente de Beauvais en particular, en los pedagogos más cualificados de la primera mitad del siglo XIII.

\section{BIOTOPOGRAFÍA BELLOVACENSE}

¿Quién fue realmente Vicente de Beauvais? No son muchos los datos ciertos que conocemos de su vida. Jacques Quetif y Jacobo Echard, sus biógrafos más sólidos, sostenían en una publicación póstuma de comienzos del siglo XVIII: «es asombroso cuántas tinieblas han echado sobre su vida los historiadores y cuántas cosas falsas se han mezclado con las pocas verdaderas $»^{2}$. En la misma línea, Marie-Dominique Chapotin se preguntaba a finales del XIX: «¿quién levantará el velo que esconde los orígenes de Vicente de Beauvais? $\gg^{3}$. Una incertidumbre que el siglo XX, a pesar de haber quintuplicado el interés por nuestro personaje, apenas ha conseguido dilucidar.

Se sabe que nació en torno a 1190 en la diócesis de Beauvais, él mismo se denomina Frater Vincentius Belvacensis en varias de sus obras. Hacia 1215, se trasladó a París en busca de ciencia y títulos académicos, hospedándose en el colegio de san Quintín. Aquí entró en contacto con la Orden de Predicadores y conoció personalmente a santo Domingo. En 1218, los documentos ya nos lo muestran formando parte de la treintena de maestros y estudiantes que componían el embrión de lo que unos pocos años después sería el celebérrimo convento dominico de Saint-Jacques de París ${ }^{4}$.

En la ciudad del Sena permaneció hasta 1229, año de la gran huelga universitaria que paralizó la universidad. De esos años apenas sabemos nada, excepto que se empapó del magisterio académico de los llamados maestros de primera generación: Guillermo de Auxerre (1144-1231), Alejandro de Hales (11851245) y Felipe el Canciller (1170-1236). Una trilogía magisterial emblemática, que marcó la vida universitaria de esos años y que acertó a conformar en nuestro dominico una personalidad más didáctica que especulativa.

2 Jacques QUETIF y Jacobo ECHARD, F. Vincentius Bellovacensis, en Scriptores Ordinis Praedicatorum recensiti, Paris, 1719, p. 212.

3 Marie-Dominique CHAPOTIN, Histoire des Dominicains de la Province de France, Imprimerie Cagniard, Rouen, 1895, p. 356.

4 Marie-Dominique CHAPOTIN, Histoire... [ver n. 3], p. 6. 
Hacia 1230, fue enviado a consolidar la casa de Beauvais, erigida en 1225, con el cargo de lector conventual. El estudio, la predicación y la enseñanza fueron sus ocupaciones prioritarias. Actividades que le granjearon una aureola de fama y reconocimiento que le abrió las puertas de la corte de Luis IX de Francia. El monarca, impresionado por su autoridad y saber, le llamó para predicar en la abadía cisterciense de Royaumont, le nombró lector de los monjes, maestro extraordinario de la familia real -Domesticus familiaris- y le posibilitó cuantiosos medios para el estudio y publicación de sus obras. De esta época data su Liber gratiae (c. 1243)5 , y sus escritos marianos más emblemáticos: Liber de laudibus beatae Mariae Virginis ${ }^{6}$ (c. 1242) y Expositio salutationis angelicae (c. 1243) ${ }^{7}$; aquí dio forma a sus famosos escritos enciclopédicos: Speculum maius, con sus tres partes: Speculun naturale, doctrinale e historiale (1244-1257) ${ }^{8}$; y fue en Royaumont donde escribió su aportación pedagógica más notable: De eruditione filiorum nobilium $(1247)^{9}$, dedicada a formar a los hijos de Luis IX de Francia.

Los últimos años de su vida los pasó entre el convento de Beauvais y el convento parisino de Saint-Jacques, dedicado a la enseñanza y a la publicación de sus últimas obras: Liber consolatorius de morte amici $(1260)^{10}$, escrito para mitigar la depresión del monarca tras la muerte de su hijo primogénito, y De morali institutione principis $(1263)^{11}$, dedicada a Teobaldo II de Navarra, yerno de Luis IX, para ilustrarle en la educación de aquellos que participan en los asuntos de la corte. La fecha de su muerte no se conoce con exactitud, aunque se ha tomado como más probable 1264. Así lo dice Luis de Valladolid en su catálogo de los escritores de la orden dominica, publicado en $1413^{12}$.

5 J. AmerbaCH (ed.), Vicentius Bellovacensis Opuscula. Scilicet: Libri de gratiae: Libri laudum Virginis gloriose: Liber de sancto fohanne evangelista: Liber de eruditione puerorum regalium: Liber consolatorius de morte amici, Basel, 1481.

6 Se publicó en J. AMERBACH (ed.), Vicentius... [ver n. 5].

7 Breve resumen en J. QUETIF y J. ECHARD, F., Vincentius... [ver n. 2], p. 238.

8 Vicente DE BEAUVAIS, Speculum maius; naturale, doctrinale et bistoriale, Bibliotheca mundi. Ex officina Typographica Balthazaris Belleri in Circino aureo, Duaci, MDCXXIV.

9 Vicente DE BEAUvaIs, Tratado sobre la formación de los bijos de los nobles (1246). De eruditione filiorum nobilium. Estudio, traducción y notas Ildefonso ADEVA y Javier VERGARA, BAC-UNED, Madrid, 2011.

10 Vicente DE BEAUVAIS, Epístola consolatoria por la muerte de un amigo. Estudio, introducción y notas por Javier VERGARA y Francisco CALERO, BAC-UNED, Madrid, 2006.

11 Vicente DE BEAUVAIS, De la formación moral del príncipe, edición bilingüe preparada por Teresa PABÓN DE ACUÑa, BAC-UNED, Madrid, 2008.

12 Guillaume Louis FigUIER, Vie des savants, vol. II: Savants du Moyen Agge, Librairie Hachette, Paris, 1870, p. 229. 


\section{DIMENSIÓN HISTORICISTA}

Vicente de Beauvais no es un filósofo ni un teólogo caracterizado por una sistemática especulativa y abstracta. Fue un compilador de la cultura que se apoya en la autoridad didáctica de los hechos históricos para construir con materiales viejos ideas nuevas. Con frecuencia, se confiesa un mero y simple recopilador de hechos ejemplarizantes, incluso resulta difícil saber si una idea es de su propiedad o un simple préstamo cultural. Situación relativamente normal en no pocos escritores anteriores a la primera mitad del siglo XIII, donde sus juicios y opiniones se hallan ligados cuando no determinados por la memoria del pasado. Esta praxis marca la personalidad didáctica de Vicente de Beauvais. Estamos ante un compilador del saber que se esforzó por ver el hilo conductor de las cosas, que se sirvió del recurso a los florilegios para sistematizar los contenidos, y que intentó descubrir las relaciones de unas materias con otras, armonizando los elementos más diversos en una perfecta concordancia.

Para él la tradición tenía un valor pedagógico insoslayable. Como buen aristotélico, defenderá que nada existe, nada se hace en ningún orden de cosas que no tenga su causa, su razón de ser y sus principios esenciales en lo que le precede. Captar el valor perfectivo de ese pasado constituyó la razón de su trabajo. Por eso su obra no alcanzó la proyección, la creatividad y la altura intelectual de otros ilustres dominicos como Juan de Wildeshausen, el Teutónico, Raimundo de Peñafort, Alberto Magno, Tomás de Aquino, etc. Su misión no era especulativa, era más bien compiladora y sobre todo didáctica. Consciente de su responsabilidad, en el capítulo IV del Libellus apologeticus, confesó abiertamente que aunque por el método su obra era innovadora no lo podía ser por las ideas, éstas eran antiguas, pertenecían al pasado ${ }^{13}$.

Indudablemente el principio de causalidad no justificaba por sí solo la posición historicista de nuestro pedagogo. Había una razón más profunda: la visión soteriológica o salvífica de la misma historia. Piensa que el conocimiento del hombre y de su obra es la historia misma de la salvación humana, marcada por la sucesión de tres momentos determinantes: creación, caída y restauración. Este último será el punto esencial que justificará la totalidad de su obra. Se trataba de buscar en los sucesos cósmicos y en los comportamientos humanos de la historia

13 Vicente DE BEAUVAIS, El «Libellus apologeticus». Un símbolo del enciclopedismo medieval. (Estudio, traducción y notas por Javier VERGARA), Educación XXI, UNED, nº 6 (2003), 149-202, cap. IV: De utilitate operis et apologia auctoris, col. 4, a. 
los registros didácticos que han marcado las formas y modos de acercarnos al conocimiento y unión con Dios.

Una idea de tremenda trascendencia metodológica y hermenéutica, que marcó las fuentes y el modo de hacer historia. Para Vicente de Beauvais, el historiador debe acercarse al pasado a través de aquellas fuentes que han mostrado con mayor seguridad y acierto los registros de la salvación humana. Un criterio selectivo que le llevó fijar una jerarquía documental de siete grados de fiabilidad descendente: Sagradas escrituras, decretos papales, cánones, legislación conciliar, escritos de los Padres de la Iglesia, escritores cristianos no canonizados, y autores paganos ${ }^{14}$. Jerarquía que completó señalando tres modos didácticos de interpretar los hechos históricos: literal, alegórico y tropológico. En el siglo XIII, hombres como Guiberto Noguent, Hugo de Saint-Cher y Tomás de Aquino añadieron una cuarta posibilidad: la anagónica o mística, pero ésta apenas alcanzó a Vicente ${ }^{15}$.

Con esta apuesta, no puede catalogarse a nuestro personaje como un historiador preocupado por la acribia rigurosa, exacta y literal de los acontecimientos. Su interés por la historia fue didáctico y en última instancia moral, religioso y trascendente. Su discurso es una continua parénesis exhortatoria orientada a generar ideales de virtud. Consciente de ello, advierte al lector que sus citas no tienen el mismo valor ni grado de veracidad; por eso las divide en importantes, regulares, insignificantes y carentes de autenticidad ${ }^{16}$. Habitualmente corta párrafos, intercala pensamientos de otros autores, atribuye ideas de forma equivocada, une párrafos discontinuos, insignificantes y carentes de autenticidad. Críticas ciertas que en su caso no revelan tanto una falta de escrupulosidad histórica como el modo de citar propio de la Edad Media. Su fino espíritu crítico le llevó a lamentar que trabajos de san Agustín, san Jerónimo o san Juan Crisóstomo hubiesen sido, por ignorancia, atribuidos a san Gregorio y san Isidoro o viceversa ${ }^{17}$; del mismo modo, muchos errores de trascripción -muy comunes en el mundo medieval- los explicó diciendo que fueron debidos a la diversidad de escribanos y amanuenses que trabajaron en su obra ${ }^{18}$, aunque matizó -con un sentido más voluntarista que real- que las imprecisiones no alteraban el sentido y la idea originaria de los autores $\operatorname{citados}^{19}$.

14 Libellus apologeticus... [ver n. 13], cap. XI: De impari auctoritate eorum quae excerpta sunt, col. 9, c.

15 De eruditione... [ver n. 9],15, 4.1.

16 Libellus apologeticus... [ver n. 13], cap. XI: De impari auctoritate eorum, quae excerpta sunt, col. 9, c.

17 Libellus apologeticus... [ver n. 13], cap. I: De causa suscepti operis et eius materia, col. 1, c-d.

18 De eruditione... [ver n. 9], 18, 4.

19 Libellus apologeticus... [ver n. 13], cap. III: De modo agendi et titulo libri, col. 3, c. 


\section{BÚSQUEDA DE LA SABIDURÍA}

Con este planteamiento metodológico, la primera preocupación que le interesó fue significar y recrearse en el fin de la educación. Una teleología recurrente que como buen dominico cifró en alcanzar la sabiduría. Aristóteles ya sostenía que «todos los hombres por su propia naturaleza desean saber» [Metafísica, A1, 980 a, 22]. La cultura veterotestamentaria consideraba la sabiduría el bien más preciado del hombre: «Vale más que las piedras preciosas» [Prov 8,11]. Cicerón, en De officis, sostendrá que es la primera de las virtudes, «la ciencia de las cosas divinas y humanas» [De offic. 1, XLVIII], y Hugo de San Víctor, en el alborear de la Baja Edad Media, recalcará: «De entre todas aquellas cosas a las que debemos aspirar, la primera es la sabiduría, en la que reside la regla del bien perfecto ${ }^{20}$. Una constante que nuestro bellovaco retomó con empeño renovado, afirmando: «el máximo consuelo en la vida es el afán por la sabiduría, el que la encuentra es feliz, y el que la posee es bienaventurado» ${ }^{21}$. Desiderátum que intentó actualizar con el descubrimiento de la verdad por la vía del entendimiento, que se fortalecía con el bien por la práctica de la virtud, y que se consolidaba con la ayuda de Dios, a través de la gracia santificante. Tríada insoslayable que le permitió elaborar una de las síntesis más logradas que hasta entonces se habían hecho entre moral, ciencia y fe.

\section{IV.1. La función de la inteligencia}

En esa aventura, su punto de partida fue la inteligencia. Con citas de Boecio y Hugo de San Víctor, dirá que estamos ante el ornato más bello del alma, el atributo más parecido a la divinidad que tiene el hombre. Una luz superior creada por Dios, impresa en la criatura humana en el momento de su creación, y participada por el hombre para captar las esencias de las cosas, trascender la materialidad de lo creado y acceder a la verdad y el bien perfecto. Idea que desarrollarán con brillantez y extensión dominicos de segunda generación como Alberto Magno y Tomás de Aquino, y que nuestro bellovaco resumirá en una conclusión escueta y contundente: Dios, suprema y total verdad, era

20 Hugo de San Victor, Didascalicon de Studio Legendi (afán por el estudio). (Introducción, estudio preliminar, traducción y notas de Carmen MUÑOZ GAMERO y María Luisa ARRIBAS), BACUNED, Madrid, 2011, I, I, 6.

21 Speculum doctrinale... [ver n. 8], lib. I, cap. II. 
el principio y el fin de la inteligencia; fuera de él, el conocimiento era vano y carecía de sentido ${ }^{22}$.

Esta tesis fue implementada por la escolástica por diferentes vías, pero nuestro dominico la resumió en la teoría de la refracción gnoseológica indirecta. Dios al crear la multiplicidad formal de la naturaleza y manifestarse en las Sagradas Escrituras ha reflejado en un gran espejo su voluntad y su ser para que el hombre, en las contingencias de la vida, mediante el pensamiento, la meditación y la contemplación, pudiera disfrutar de la antesala de la felicidad eterna. Fue san Pablo, en la Primera Carta a los corintios, quien sancionó esta tesis al afirmar: «vemos ahora mediante un espejo, confusamente; entonces veremos cara a cara» [1 Cor 13,12]. Los Padres de la Iglesia, Gregorio de Nisa y especialmente san Agustín al hablar del speculum cogitationis y del speculum mentis ${ }^{23}$, insistirán en ello. Aunque será la Baja Edad Media quien la sistematice y genere los libros-espejo más diversos: Speculum ecclesiae, de Honorius Augustodinensis, c. 1109; Speculum virginum, c. 1127, de Conrado de Hirsau; Speculum universale, de Raoul Ardent, c. 1199; Speculum futurorum temporum, de Gébénon de Eberbach, c. 1220; Speculum novitii, de Etienne de Sally, 1234. Un largo elenco, cuyo símbolo más acabado será sin duda el Speculum maius (c. 1246) de Vicente de Beauvais. En el capítulo VI de su prólogo -el libellus apologeticus- está resumido el sentido del enciclopedismo y de la refracción indirecta medieval:

Pienso -dirá Vicente- que nadie estimará superflua o inútil la naturaleza misma de las cosas, que yo he descrito lo mejor que pude; nadie, digo, que, iluminado por la verdad misma, esté acostumbrado a leer en el propio libro de la creación, puesto ahí para que leamos el poder, la sabiduría y la bondad de Dios, creador, gobernador y conservador de todas las cosas. Pues, como dice el gran Basilio, Aquellos que entienden la verdad y por las cosas visibles deducen las invisibles, aprecian la obra de nuestro benefactor en la tierra, en el agua, en el aire, en el cielo, y en todo lo que ven. Así, unido estrechamente el Señor a sus sentidos, ni se les da ocasión de pecar, ni se da lugar al enemigo para que sugiera cosas contrarias ${ }^{24}$.

Esta apuesta, que liga naturaleza, ciencia y Dios, dio lugar a dos consecuencias prácticas de suma relevancia. Por un lado, la naturaleza ya no será una entelequia incausada y ordenadora del universo -como la llamaba Platón en el

22 Speculum doctrinale... [ver n. 8], lib. I, caps. 19-21; 22-23 у 29.

23 Agustín, De trinitate, XV, 20, 39; XV 24, 44. [Migne, Patrología Latina (M.42)]; Soliloquios (II, 6-10).

24 Libellus apologeticus... [ver n. 13], cap. VI: Apologia de natura rerum et historia temporum. 
Time $0^{25}$-, ni un concepto difuso y de difícil comprensión, como lo llamaba Cicerón en De inventione ${ }^{26}$, será una creación divina, preñada de ilusión y esperanza, cuya radicalidad más genuina consistirá en reflejar de forma indirecta, en su multiplicidad y singularidad formal, la voluntad, el sentimiento y el ser de Dios, para hacer feliz al hombre y llevarlo a la eternidad. Vicente, dirá con san Jerónimo: «Aprendamos en la tierra la ciencia de aquello que perseverará con nosotros en el cielo», pues el saber sólo se desvanece en cuanto a la forma e imperfección, pero no en cuanto a su sustancia ${ }^{27}$. Por otro, esa diversidad formal, en tanto que reflejo indirecto de Dios, se presentaba como el contenido óptimo de la ciencia y del aprendizaje, era la gran posibilidad humana. Un juicio firme que llevará a Vicente de Beauvais a concluir: la restauración espiritual del hombre se operaba por la ciencia o doctrina: «et quoniam ipsa restitutio sive restauratio per doctrinam efficitur, atque perficitu» ${ }^{28}$.

\section{IV.2. La educación moral}

El segundo de los ejes que sustancia la actualización de la sabiduría es el bien. Se trata del fin al que por naturaleza tienden todos los seres humanos, su principio dinámico fundamental. Una posesión que en su grado sumo los escolásticos denominaron felicidad y en su realización práctica virtud.

¿Pero, qué entendió nuestro bellovacense por virtud? Siguiendo su costumbre, no entró en intrincados y complejos recorridos especulativos. Mostró su concepción con ejemplos prácticos, extraídos del pensamiento grecorromano, patrístico y medieval, de los cuales sí se deriva una sistemática y teoría, que se puede sintetizar en tres principios marco.

En primer lugar, entenderá por virtud una fuerza o disposición del alma, impresa en el hombre en el momento de su creación y orientada, por la virtualidad de los hábitos operativos buenos, a la perfección de sus potencias, especialmente de la inteligencia y la voluntad, para predisponer sus afectos, emociones e impulsos a la práctica del bien ${ }^{29}$. Tarea compleja y ardua que demandaba, por un lado, la sindéresis o capacidad de distinguir entre el bien y el mal; y, por otro, la idea

25 Platón, Timeo, $35 \mathrm{ab}$.

26 CicERón, De inventione. I, 34.

27 JerónImo, Epistolae, LIII, 9. De eruditione... [ver n. 9], 12,4.2.

28 Speculum doctrinale... [ver n. 8], lib. I, col. 2.

29 Speculum doctrinale... [ver n. 8], lib. IV, cap. 3. 
clara y distinta de que el mal no tiene entidad por sí mismo, nada bueno o útil puede derivarse de él, no se relaciona con la perfección, implica defecto, debilidad o carencia ${ }^{30}$. Una convicción firme, que le llevó a concluir con san Agustín que el estado ideal del hombre en cuanto hombre es el estado de virtud, el estado de bien, que es lo más acabado y perfecto del $\operatorname{ser}^{31}$. Sin virtud, el saber se debilita, la ciencia o doctrina es vana; no lleva a la felicidad, no hace al hombre libre, no lo transforma. Por eso, con Lactancio, concluirá: la «virtud unida a la ciencia es la sabiduría $\gg^{32}$. Tesis que le llevará a fijar una de las definiciones más sólidas que hasta entonces se habían hecho sobre el concepto de formación. Una categoría inmanente, que denominó «eruditio», orientada a transformar interiormente al hombre (eruditio), por la virtualidad de dos categorías: la ciencia o doctrina (instructio), que atiende al juicio o razonamiento (ingenium), y la educatio o disciplina, que se orienta al bien o dimensión moral (virtus) ${ }^{33}$.

En segundo lugar, por influencia paulina, paleocristina y escolástica, defenderá que la virtud no es un fin en sí mismo, como defendían los estoicos romanos. Tiene un significado de alteridad, es una relación medial donativa que tendría en la caridad el principio y el fin de la felicidad: $\ll$ Si no tengo amor, de nada me sirve hablar todos los idiomas del mundo, y hasta el idioma de los ángeles. [...] ;soy como una campana desafinada!» [1 Cor 13,1]. Una donación, en cualquier caso libre y corresponsable, donde la optimización de la acción y la mejora intrínseca del otro constituye su plasmación más radical. Vicente, dirá con san Bernardo: «Si la ciencia [...] no está cocida con el fuego de la caridad, ensoberbece, igual que la comida mal digerida produce malos humores y no nutre al cuerpo, sino que más bien lo corrompe $\gg^{34}$. Principio que encontró su expresión más acabada en la donación de los santos y de Cristo. En ellos estaba representada la suma perfección, una meta que han ganado por la aceptación voluntaria, paciente y esperanzada de la virtud como relación donativa. Por eso invitará con avidez a engarzarla en el corazón del hombre, a incorporarla por el uso y ejercicio a la naturaleza ${ }^{35}$.

En tercer lugar, dejó claro que el conocimiento de la felicidad o del ser no produce el acceso directo o posesión automática del bien, aunque lo presuponga y se ordene a ello. El conocer es propio de la razón; en cambio, el bien es fruto de la

30 Speculum doctrinale... [ver n. 8], lib. I, caps. 23-4.

31 Agustín, Sermones, XX, 4: PL 38, 141; De eruditione... [ver n. 9], 24,3.

32 LaCTancio, Divinae institutiones, III: PL 6, 369B. De eruditione... [ver n. 9], 23,1.2.

33 De eruditione... [ver n. 9], 1,2 y 1.3.1-2.

34 Bernardo, Sermones in Cantica, XXXVI, 4: PL 183, 969A (1400). De eruditione... [ver n. 9], 23, 1, 1.

35 De eruditione... [ver n. 9], 27,5.6. 
acción, del obrar humano, de la virtus. Un principio axial que cifró en la fuerza de la educatio o disciplina, y, más en concreto, en la sujeción a norma ${ }^{36}$. Tarea ardua y compleja que exigía la anuencia de tres condiciones. En primer lugar, convertir la acción en hábito por medio de la costumbre para lograr una metanoia progresiva, una nueva índole o imagen virtuosa que lleve, de acuerdo con Cicerón, a una segunda naturaleza: Consuetudo quasi altera natura [De finibus 5, 25, 74], a un nuevo ethos que por su misma entidad permite afirmar el espíritu y practicar la virtud ${ }^{37}$. En segundo lugar, se requiere la aceptación voluntaria y libre de la disciplina. En esa libertad radica la esencia de la virtud, una posibilidad que transforma la necesidad en virtud. «El hombre bueno -dirá con Séneca- soportará con ánimo sereno cuanto le sucediere; pues sabrá que eso ha ocurrido por la ley divina, con la que todas las cosas funcionan $\gg^{38}$. Finalmente, el bien requiere la constancia permanente de la disciplina. La virtud no se tiene ni se posee en propiedad o plenitud al modo de una categoría material, simplemente se mantiene. Con Séneca, recalcará: «las imperfecciones tienen necesariamente que aparecer $\gg^{39}$, forman parte del hombre, se nace con ellas y con ellas se muere; e incluso, cuando se superan y dominan, aún debe mantenerse el uso de la disciplina, pues, como afirmaba Horacio, «aunque expulses el natural a golpes de horca, él volverá siempre». Lo único que cabe es domarlo, sujetarlo a norma y corregirlo para aspirar a que las caídas e imperfecciones de la vida sean ocasionales y, si se puede, excepcionales ${ }^{40}$.

\section{IV.3. La virtualidad de la fe}

El tercer elemento que sustancia el trípode de la felicidad es la fe. Un tema mollar al que nuestro polígrafo dedicó un trabajo específico, el Liber gratiae (c. 1244), repetido en parte en numerosos pasajes del Speculum maius y del De eruditione.

Sin entrar en demasiados análisis especulativos, pondrá de manifiesto cómo la antropología clásica había hecho del hombre un esclavo de su propia voluntad y un ser sujeto a la autoridad exclusiva y única de la inteligencia. Apostar por un planteamiento semejante no sólo suponía limitar la naturaleza, sino olvidar el

\footnotetext{
36 De eruditione... [ver n. 9], 25, 1.

37 De eruditione... [ver n. 9], 23,9-23,10.

38 SÉNECA, Epistolae, 76, 23. 8. De eruditione... [ver n. 9], 27,2.2.

39 SÉNECA, Epistolae, 71, 35, De eruditione... [ver n. 9], 23,11.1.

40 Horacio, Epistolae, I, 10, 24. De eruditione... [ver n. 9], 23,10.
} 
daño mistérico e insondable del pecado original. Un daño que había debilitado la inteligencia y la voluntad humanas, haciéndolas radicalmente incapaces de pasar por sus solas fuerzas de un plano natural a otro sobrenatural, posibilidad que sólo se alcanzaba con la fuerza de la fe. Por eso, con la ayuda de san Agustín, sostendrá que negar esta verdad suponía un acto de idolatría, una manifestación de soberbia y una desobediencia manifiesta. El primero y mayor vicio para la perdición del hombre consiste en querer valerse de la propia y exclusiva autoridad. El nombre de ese vicio se llama desobediencia ${ }^{41}$. En la misma línea, con Pseudo Dionisio Areopagita, recalcó que el entendimiento era la parte más noble del alma, pero por sí solo no podía desentrañar los misterios insondables de la naturaleza, de la divinidad, necesitaba del fundamento de la fe $\mathrm{fe}^{42}$.

Una unidad entre razón y fe, entre ciencia y teología, que se alejaba del narcisismo moral e intelectual grecorromano y se aferraba al valor complementario y restaurador de la gracia. Cristo con su encarnación, muerte y resurrección ha justificado al hombre, le ha devuelto la esperanza de la verdad y le ha brindado la posibilidad de la restauración y felicidad. «La debilidad de la naturaleza -dirá Vicente- se salva mediante los sacramentos de Cristo» ${ }^{43}$. Para él la fe es voluntad divina que se prende en el alma humana y le insufla la energía que le falta para conocer la verdad y mover la voluntad al bien, adelantando en las contingencias de la vida terrena el sentido de la felicidad celestial. Se trata, por tanto, del valor más extraordinario del ser humano; algo incluso más valioso que el propio hombre con su dignidad personal y moral. Es el mismo Dios que habita en el alma del hombre y le dispone libérrimamente a abrazar el bien ${ }^{44}$.

\section{LOS AGENTES PERSONALES DE LA EDUCACIÓN}

\section{V.1. La figura del maestro}

Tras recrearse en el fin de la educación, Vicente se adentró en los elementos personales del proceso educativo, comenzando su tarea por la figura del maestro. Término que designó con distintos nombres: magister, lector, doctor, gramaticus,

41 Agustín, De Genesi ad Litteram, vIII, 6,12. De eruditione... [ver n. 9], 22,6.1.

42 Dionisio Areopagita, De divinis nominibus 4, 7, PG 3, 701C. Speculum naturale... [ver n. 8], lib. $1^{\circ}$, cap. IV.

43 Agustín, De civitate Dei, XXI, 16. De eruditione... [ver n. 9], 35,5.1.

44 De eruditione... [ver n. 9], 35,5.2. 
etc. y que trató en diferentes lugares del libro segundo del Speculum doctrinale y en los capítulos II, III, VII y VIII del De eruditione. Referentes donde, con ayuda de Agustín de Hipona y el De disciplina scholarium del Pseudo-Boecio, hizo una de las síntesis más logradas sobre la figura y función del maestro escolástico, sirviendo de base didáctica al Christus, unus omnium magister (1257) de san Buenaventura y a la cuestión 11 del De veritate de Tomás de Aquino (1256-1259), considerados por la historiografía filosófica corolario y síntesis del magisterio bajomedieval.

En esa apuesta, será un claro y fiel reflejo de la tradición. Con san Agustín, dirá que Dios al asentarse y habitar en el interior del hombre desde el momento de su creación es la causa principal de toda forma de conocimiento y de aprendizaje, por lo que en sentido estricto «solo a él debemos llamar con propiedad maestro $\gg^{45}$. Pero, a renglón seguido, planteará un tema de especial trascendencia: la necesidad de reconocer el verdadero ser de las criaturas. Aquí radica una de sus grandes aportaciones. Para el bellovacense, como pocos años después dirá Tomás de Aquino en la cuestión 117 de su Suma teológica, la grandeza de Dios radica en crear seres que puedan colaborar en su obra creadora, pedagógica y corredentora, que sean sus causas segundas, en definitiva, que puedan enseñar. Este es el sentido de la perícopa bíblica: Id y enseñad a todas las gentes [Mt 28,19-20]. Un proceso en el que Dios es la luz y causa primera que imprime los principios en el alma humana y el maestro causa segunda que por su experiencia y saber posibilita al discípulo llegar a conclusiones, pasar de la potencia al acto, de la ignorancia al saber y al obrar. A esto se llama aprendizaje ${ }^{46}$.

En el dinamismo cultural de la primera mitad del siglo XIII plantear esta tesis no era ocioso ni retórico. Vicente quiere asegurar la imagen del maestro cristiano, evitar su secularidad y su desvirtuación. Es consciente que en la nueva sensibilidad muchos querían aprender sin pasar por la escuela, aprender sin maestro, olvidar la tradición: eran los autodidactas, los nuevos mentores de la invención. La cuestión no era baladí, Pedro Abelardo ya se había hecho eco de ello en el siglo anterior con su Historia calamitatum (c. 1132), el Pseudo-Boecio a finales del siglo XII repetía parecidas críticas, y ahora nuestro dominico afirmará con contundencia: sin el maestro no hay método y sin método no hay eficacia. Con la ayuda del De Viris Illustribus de san Jerónimo, recalcará: «Quien no sigue a otro que va delante, se hace a sí mismo un pésimo maestro» ${ }^{47}$. Y, con Séneca, concluirá: «Los ciegos buscan un guía; nosotros en cambio sin guía vagamos

45 De eruditione... [ver n. 9], 3, 28, 4

46 Speculum doctrinale... [ver n. 8], lib. V, cap. 53.

47 Jerónimo, De Viris Illustribus. PL, 23, 603B (822). De eruditione... [ver n. 9], 7,2.1. 
errantes y por eso difícilmente alcanzamos la salud, porque no sabemos siquiera que estamos enfermos» ${ }^{48}$.

Pero Vicente no era un filósofo de la educación. Sin renegar de la especulación, le interesó más la didáctica del magisterio. Una preocupación que sintetizó en cinco cualidades parenéticas que pueden considerarse el sillar y base del magisterio posterior: mente ingeniosa, vida honesta, ciencia humilde, elocuencia sencilla y pericia docente ${ }^{49}$.

Por mente ingeniosa, entendió la capacidad innovadora y creativa del maestro. Este, aunque en buena parte extraía su ciencia y su saber de la memoria y experiencia del pasado, debía superar la propia historia siendo innovador y creativo. Con esta idea se situaba en parámetros vanguardistas de la didáctica de su tiempo. Unos referentes donde la lectio, que desde el siglo VI había sido la base de la enseñanza altomedieval, dejaba paso a la quaestio posibilitando una pedagogía más personal e innovadora. Un salto didáctico que dio lugar a la aparición de uno de los signos más característicos de la escolástica: las escuelas. En ellas, al lado de la materia prima del texto, empezó a primar la explicación y opinión individual del maestro. Por eso, con el Pseudo-Varrón, aconsejará: «Elige como formador a aquel a quien admires más por sus propias ideas que por las ajenas. Nada importante enseñará quien nada ha aprendido por su cuenta. Y sin razón se llama maestros a los repetidores de lo que han oído; y deben ser oídos como el que propaga rumores ${ }^{50}$. Idea de considerable calado que llevó a los discípulos a ser definidos por la imagen del maestro que elegían, de ahí los nombres de: Porretanos en honor de Gilberto Porreta, Albericanos por Alberico de Reims, Meladinenses por Roberto Melun, Victorinos por Hugo de San Víctor, etc.

$\mathrm{El}$ segundo requisito era vida honesta. Una causa ejemplar insoslayable que demandaba tres cualidades: primero, hacer del comportamiento un reflejo del espíritu, para que no ocurriese la sentencia de Séneca: «es muy vergonzoso esto que se nos suele imputar a nosotros los filósofos: que cultivamos los términos de la filosofía y no sus obras ${ }^{51}$; segundo, era de todo punto necesario impregnar el magisterio de sentido ético, para no reflejar la sospecha de san Ambrosio: «las hojas sin fruto me resultan sospechosas, pues tal vestido lo llevan los desterrados del paraíso ${ }^{52}$;

48 SÉNECA, Epistolae, 50, 3-4. De eruditione... [ver n. 9], 7,2.1.

49 Speculum doctrinale... [ver n. 8], v, 53: De gratia docendi, col. 434; 54-55: De forma vel modo docendi, col. 435; De eodem, col. 535s. De eruditione... [ver n. 9], 2,2.0.

50 PSEudo-VArrón, Sententiae, 53, 67, 68. De eruditione... [ver n. 9], 2,2.1.

51 SÉNECA, Epistolae, 24, 15. De eruditione... [ver n. 9], 2,3.1.

52 Ambrosio, Expositio in Lucam, X, 45: PL 15, 1814D. De eruditione... [ver n. 9], 2,3.1. 
finalmente, se requería hacer de la virtud un carácter o segunda naturaleza, de tal manera que se pueda decir el dicho del Pseudo-Boecio: «Quien desee cumplir el oficio de maestro es preciso que goce de gran prestigio por su total honestidad de costumbres. Esté siempre de buen talante, sea piadoso en sus sentimientos, insigne por sus virtudes y loable por su bondad $»^{53}$.

La tercera exigencia la cifró en la ciencia humilde. Una condición que requiere tiempo, esfuerzo y paciencia: «Aprende durante mucho tiempo aquello que hayas de enseñar» ${ }^{54}$; «fue disciplina de los pitagóricos callar durante cinco años y después, ya formados, hablar ${ }^{55}$. Posibilidad que demanda sobremanera prudencia extrema en el hablar: «la ciencia hincha, la caridad edifica. Si alguno cree saber algo, aún no sabe cómo conviene saber» [1 Cor 8,1-2]. Tal es la ciencia de los demonios, por la cual se llaman así, pues daimon quiere decir «el que sabe» o «el que cree saber ${ }^{56}$. Apreciaciones no exentas de cierta crítica hacia un mal de su tiempo: la necedad de los charlatanes, que sin conocer los fundamentos de una ciencia se atrevían a discutir afanosamente sobre ella. Por eso, concluye con Quintiliano: «Las artes serían más felices, si sobre ellas sólo opinaran los artistas ${ }^{57}$.

El cuarto requisito se refería a la elocuencia sencilla, aquella que evita la sofística y busca la verdad en la palabra ${ }^{58}$; la que se hace sin acaloramiento y serenidad; con voz y gestos adecuados y evita extender los brazos, patear el suelo y agitar el cuerpo ${ }^{59}$; la que ignora el litigio, la aclamación pública y la complicidad del griterío ${ }^{60} ; \mathrm{y}$, sobre todo, la que se apoya en la seguridad de conciencia y en la alegría de espíritu, pues ésta da a la elocuencia lo que el ingenio le niega ${ }^{61}$. Una cualidad rara de su tiempo, que le llevó a afirmar: «De entre muchos miles apenas se encuentra hoy día alguno que sea comedido en la elocuencia; por el contrario, casi todos se acaloran y porfían, y en consecuencia enturbian más que aclaran la verdad. A esto lleva sobre todo la ambición de vanagloria o la disimulación de la propia ignorancia» ${ }^{62}$.

53 Pseudo-Boecio, De Disciplina scholarium, vI: PL. 64, 1235 B. De eruditione... [ver n. 9], 2,3.3.

54 Jerónimo, Epistolae, CXXV: Ad Rusticum monachum, 18: PL 22,1082 (945). De eruditione... [ver n. 9], 2,4.1.

55 JerónImo, Commentaria in Ecclesiasten: PL 23, 1037B (410), De eruditione... [ver n. 9], 2,4.1.

56 De eruditione... [ver n. 9], 2,4.2.

57 QUINTILIANO, Institutio oratoria, XII, 10, 50. De eruditione... [ver n. 9], 20,3.1.

58 QuinTILIANO, Institutio Oratoria, II, 15, 32. De eruditione... [ver n. 9], 21,2.2.

59 Speculum doctrinale... [ver n. 8], lib. v, caps. 54 y 55. De eruditione... [ver n. 9], 2,6.5.

60 De eruditione... [ver n. 9], 21,7.

61 Speculum doctrinale... [ver n. 8], lib. v, caps. 54 y 55. De eruditione... [ver n. 9], 2,6.5.

62 De eruditione... [ver n. 9], 21,1.1. 
El quinto y último requisito es la pericia. Una cualidad a la que se le demanda claridad: «debe ser tan claro el lenguaje del que enseña que no excluya a nadie de su comprensión ${ }^{63}$, ello exige evitar palabras novedosas, llegar con deleite al corazón de todos los oyentes y ser «como la moneda que tiene una acuñación pública» ${ }^{64}$; debe ser igualmente dinámica y diversa, «pues en todas las cosas la igualdad engendra aburrimiento ${ }^{65}$; debe tener brevedad moderada porque «la prolijidad excesiva embota los sentidos y la brevedad exagerada corta de raíz el interés por los estudiosos» ${ }^{66}$. Un conjunto de cualidades que exigían preparar lecciones con tiempo, esfuerzo y síntesis, para así evitar las críticas de Ovidio: «Con frecuencia se queda indeciso y no sabe por dónde debe girar el caminante que por todas partes ve caminos» ${ }^{67}$.

Hasta aquí un conjunto de cualidades que Vicente resumió en un texto del Pseudo-Boecio, que puede considerarse una de las expresiones más acabadas del magisterio escolástico:

Es necesario que sea erudito, apacible y firme; ni perezoso ni arrogante. Erudito, digo, pues es preciso antes aprender que enseñar. Apacible, para que sepa aguantar, cuando sea necesario, los plantes de los alumnos. Firme, para que imponga el castigo a los que yerran, se enfrente a los protestones, desbarate a los intrigantes y reprenda a los insolentes. No sea negligente, sino celoso y diligente en el oficio de su magisterio; porque así como la constancia es la madre del éxito en cualquier obra, así también la negligencia es la madrastra de toda doctrina y disciplina. Tampoco sea arrogante, pues los arrogantes nunca enseñan con equidad, sino que desde su fastidio desprecian a los sencillos, y tienen a menos enseñar humildemente lo que saben, y no atribuyen sus conocimientos al dador de la ciencia, sino que contemplan en sí mismos la razón de su propia excelencia ${ }^{68}$.

\section{V.2. La condición de discípulo}

Al lado del maestro aparece la otra figura clave del proceso de enseñanzaaprendizaje: el discípulo, que significa el que aprende y se deja enseñar. Concepto que fue designado con distintas expresiones: discipulus, scholasticus, discens, schola-

\footnotetext{
63 Julián Pomerio, De Vita Contemplativa, I, 23: PL 59, 439A. De eruditione... [ver n. 9], 3,2.

64 QuinTILIANO, Institutio Oratoria, I, 6,3; I, 5, 71. De eruditione... [ver n. 9], 3.

65 Tulio Cicerón, De Inventione, I, 41, 76. De eruditione... [ver n. 9], 3,7.4.

66 Jerónimo, Commentaria in feremiam, II (877-878): PL 24, 717B. De eruditione... [ver n. 9], 3,5.1.

67 Ovidio, Fasti, v, 3-4. De eruditione... [ver n. 9], 3,5.2.

68 Pseudo-Boecio, De disciplina scholarium, VI: PL 64, 1235BCD. De eruditione... [ver n. 9], 3,9,0-5
} 
ris, studens... y es abordado en diferentes capítulos del libro II del Speculum doctrinale y en los capítulos IV a V y VIII a XII del De eruditione. En ellos, con ayuda del Pseudo-Boecio y Hugo de San Víctor, nuestro dominico se dirigirá a dos tipos de escolares, de entre 13 y 20 años, que cursan materias de trivium y quadrivium. Son los llamados principiantes, a los que correspondía oír, y proficientes, a los que incumbía estudiar. Los conocidos como provectos o avanzados, a los que concernía ejercitarse, y los perfectos, a los que atañía enseñar, no fueron objeto de su consideración ${ }^{69}$.

Estos estudiantes implementaban su proceso de enseñanza-aprendizaje con las técnicas didácticas propias de la época: la lectio y la quaestio. La primera, se sustanciaba en la autoridad tradicional de los textos, y se dividía en cuatro partes: introito, que servía para presentar al autor, contextualizarlo y explicar su intención; littera, consistía en la lectura y explicación de las frases o palabras contenidas en los textos; sensus, análisis o explicación que se desprendía de la simple interpretación de la littera; y sententia, que representaba la interpretación más profunda del pensamiento del autor a la luz de la historia ${ }^{70}$. Cuando una parte no quedaba clara, parecía insuficiente o generaba dudas entraba en escena la collatio. Se trataba de una evolución o complemento de la lectio que consistía en conversaciones entre maestros y estudiantes para dilucidar lo que de oscuro pudieran tener ciertos razonamientos y verdades. En ocasiones -y no era poco frecuente- el sensus y la sententia solían reforzarse con glosas, que eran comentarios sintetizados de otros autores que servían para reforzar las partes de la lectio. Un modo que, a partir del Sic et non (1122-26) de Abelardo, se enriqueció con la aportación de la quaestio, modo didáctico que pulía y dirimía las discrepancias y partes dudosas de la lectio, dando mayor entrada a las tesis del maestro.

Este es el marco docente con el que se encuentra y aprende Vicente. Un atrezo que conoce muy bien, que ha vivido en primera persona, y que le sirve para configurar tres ideas nucleares que pergeñan la imagen del discípulo ideal. En primer lugar, habla de la audibilitas o tazurnitas, cualidad que se resume en tres atributos: la importancia del silencio, la credulidad humilde y el discernimiento autónomo. «Confieso que siento dolor por algunos hombres, que viniendo a nosotros como para aprender algo [...], preguntan ciertamente como ignorantes, pero llevan la contraria como entendidos» ${ }^{71}$, «sea todo hombre pronto para oír,

69 De eruditione... [ver n. 9], 7,1.

70 Didascalicon, lib. III, C. 9, [PL. t.176, 771 D, 772.$]$

71 Pseudo-Clemente, Recognitiones, III, 33: PG 1, 1297C. De eruditione... [ver n. 9], 9,4.2. 
tardo para hablar» $[\text { St 1,19] }]^{72}$; a continuación, reivindica la importancia de la credulidad humilde, la fe en aquel que ha elegido por guía, y le permite esperar en silencio el sabor paciente de la sentencia; finalmente, la audibilitas reclama para el escolar un sentido crítico autónomo y noble, actitud que, citando a Aristóteles, le debía permitir confirmar al maestro o apartarse de sus enseñanzas si éstas contradicen una autoridad o razón de más peso $^{73}$, por eso, con la epístola a los tesalonicenses [1 Tes 5,21], concluirá: «Probadlo todo y quedaos con lo bueno» ${ }^{74}$.

La segunda cualidad del discípulo es la studiositas. Se trata del deseo firme, estructurado y ordenado que ha de presidir la vida del estudiante para dirigir sus actos a la búsqueda de la verdad. Una virtud acuñada en el De Inventione de Cicerón, con la que Vicente se sentía especialmente identificado. Studeo en sentido estricto significa celo, atención, empeño, cuidado. $Y$ aquella actividad que por su propia naturaleza más empeño, celo y orden requiere es la búsqueda de la sabiduría, bajo la autoridad atenta del maestro ${ }^{75}$. Exigencia a la que también llamó docílitas, y que no era otra cosa que la obediencia, sumisión y acatamiento libre de la voluntad del maestro ${ }^{76}$, según el dicho del Eclesiástico 32,12: «Escucha callando y a la vez preguntando» de buena fe y sin ánimo de ridiculizar o tentar ${ }^{77}$. Solo así llegarás a la verdad.

El tercer y último requisito que define la imagen del discípulo ideal era el interés o empeño por retener en la memoria. Un tema imprescindible, y más en ausencia o escasez de libros, que se tornaba de todo punto capital para el pensamiento, la reflexión y la creatividad. Vicente lo abordó desde una doble perspectiva: la natural y la artificial en el capítulo V y X del De eruditione y en el libro IV, capítulo 21 del Speculum doctrinale. Con la ayuda del De inventione de Cicerón, la Retorica ad Herennium y los libros X y XI de las Confesiones agustinianas, afirmará que aprender es captar la realidad, comprenderla, integrarla en el ser; pero se aprende no cuando se descubre la verdad y el bien, sino cuando se tienen y se rumian por la acción retentiva de la memoria ${ }^{78}$. «El corazón del fatuo -dirá citando el Eclesiástico 21,17- es como un vaso roto, no retendrá toda la sabiduría», y con el Pseudo-Varrón reiterará: «el oído que no entrega a la memoria lo que

72 De eruditione... [ver n. 9], cap. VIII, 8, 2.1.

73 ARISTÓTELES, De Sophisticis Elenchis, 2, 165b, 3. De eruditione... [ver n. 9], 8,4.2.

74 De eruditione... [ver n. 9], 8,5.

75 Speculum doctrinale... [ver n. 8], lib. v, 46, col. 430.

76 Speculum doctrinale... [ver n. 8], lib. I, 24: col.21s; 25, col. 22; V, 45: col. 430.

77 De eruditione... [ver n. 9], 9,6.

78 Speculum doctrinale... [ver n. 8], lib. IV, cap. 21: De memoria. 
capta es un canal agrietado» ${ }^{79}$. Una opción a la que rendirá cumplida pleitesía, considerando la memoria en su condición de medio y no de fin: «No te alegres demasiado, oh lector, de haber leído muchas cosas, sino de haberlas entendido y, sobre todo, de haberlas podido retener en la memoria» ${ }^{80}$.

En paralelo con esta visión natural de la memoria, quiso tratar su dimensión artificial, pero apenas concretó su dinámica funcional. Le servía el Didascalicon de studio legendi (c. 1131) y el De tribus maximis circumstantiis gestorum (c. 1135), ambas obras de Hugo de San Víctor, y auténticos bestseller de la didáctica mnemotécnica medieval. Con el auxilio del Victorino incitará al estudiante a practicar el resumen para recordar, porque todas las palabras que se dicen en una lección no pueden retenerse fácilmente, y menos las de todo un libro ${ }^{81}$. «Porque todo tratado tiene algún principio en el que se fundamenta toda la verdad de la cuestión y la fuerza de su resolución, y a él se refiere todo lo demás. Buscar esto y considerarlo es resumir. La fuente es por cierto una sola, y de ella nacen muchos riachuelos; no es necesario seguir los recovecos del río: si tienes la fuente, lo tienes todo $\gg^{82}$. A continuación, dirá que a la exigencia del resumen sigue la práctica del estudio o repaso. Hábito que cobraba más eficacia cuando se realizaba en pequeños grupos de oyentes «para que así el discípulo no sólo sepa lo que entiende, sino también aprenda a expresar lo que sabe ${ }^{83}$.

\section{EDUCACIÓN PARA LA SALUD}

Al lado de estos pilares, que tradicionalmente habían sustanciado la teoría pedagógica, Vicente de Beauvais añadió uno nuevo: la dimensión psicofísica del hombre o educación para la salud, tema especialmente innovador que desarrolló en el Speculum naturale y en menor medida en el doctrinale. Como es sabido, la cultura altomedieval había defendido una concepción antropológico-cultural donde la persona se presentaba como entidad individual y social de naturaleza moral, cognoscitiva y trascendente. La antropología escolástica, y nuestro bellovacense en particular, no renegó de ello: presentó al hombre como una unidad psicofísica de alma y cuerpo, donde las relaciones entre medicina, psicología,

79 PSeudo-VArrón, Sententiae, 91. De eruditione... [ver n. 9], 10,1.

80 Hugo de San Víctor, Didascalicon, III, 12: PL 176, 773B. De eruditione... [ver n. 9], 10,1.

81 De eruditione... [ver n. 9], 10,3.1.

82 Hugo de San Víctor, Didascalicon, III, 12. De eruditione... [ver n. 9], 10,3.2.

83 Pseudo-Boecio, De Disciplina Scholarium, v: PL 64, 1234B. De eruditione... [ver n. 9], 10,3.3. 
biología, medio ambiente, naturaleza y educación contribuían a actualizar las potencialidades del ser humano en orden a su fin último ${ }^{84}$.

Esta idea se venía ya consolidando desde finales del siglo XI, gracias a dos fenómenos de tremenda trascendencia: por un lado, la entrada en escena del llamado «nuevo Aristóteles», que significó la apuesta por una ciencia más inductiva y experimental; por otro, la asimilación progresiva de la filosofía natural y de la medicina greco-árabe, que penetró en occidente por una doble vía: en primer lugar, la salernitana, gracias a las traducciones y compilaciones de Constantino el Africano; y en segundo lugar, por la toledana, sobre todo a partir de 1187, año en que Gerardo Cremona tradujo el llamado Corpus toletanum: el Libro de la ciencia de Alfarabi (870-950), el Canon medicinae de Avicena (980-1037) y el Liber ad Almansoren de Rhazes (860-932).

Estas obras encontraron su acomodo en el inquieto naturalismo de la época, sirviendo de modelo a una emergente cultura naturalista y sanitaria, que convirtió la salud en objeto de atención de las gentes del saber de la Baja Edad Media. Para nuestro polígrafo, hablar de salud era hablar de equilibrio vital. Una máxima que desde Hipócrates y Galeno tenía mucho que ver con la interacción y armonía entre los tres vectores clave de la vida: los cuatro elementos básicos que conforman la naturaleza: fuego, aire, agua y tierra ${ }^{85}$; los cuatro humores o líquidos básicos del cuerpo: sangre, flema, bilis amarilla y bilis negra ${ }^{86}$; y las sex res non naturales o categorías necesarias para la vida y exteriores al hombre: $1^{a}$ ) la luz, el aire, la tierra y el agua; $2^{a}$ ) las comidas y bebidas; $3^{a}$ ) el trabajo y el reposo; $4^{a}$ ) el sueño y la vigilia; $5^{a}$ ) las excreciones y secreciones, que englobaban el baño, las relaciones sexuales, la flebotomía, y el ejercicio físico, y $6^{\text {a }}$ ) las disposiciones o estados del espíritu: alegría, enfado, tristeza, etc. ${ }^{87}$. La interacción y equilibrio perfecto de todo ello posibilitaría la salud; su desequilibrio o disarmonía, la enfermedad ${ }^{88}$.

Tras este planteamiento, nuestro dominico, con la ayuda de Guillermo de Conches, se adentró en un reto que muy pocos de su tiempo osaron hacer: educar la salud según las etapas psicobiológicas que jalonan la vida humana. Un tema complejo que, mutandis mutandis, concretó en las seis edades de la vida asentadas por Isidoro de Sevilla: infancia hasta los siete años, niñez o pueritia hasta los 14,

84 Speculum naturale... [ver n. 8], lib. XXXI, cap. LXIX, col. 2344.

85 Speculum doctrinale... [ver n. 8], lib. XII, cap. VI, col. 1172.

86 Speculum doctrinale... [ver n. 8], lib. XIII, cap. VI.

87 Speculum naturale... [ver n. 8], lib. XXXI, cap. LXXXV. De incolumitate. Col. 2358.

88 Speculum naturale... [ver n. 8], lib. XXXI, cap. LXXXV. De incolumitate. Col. 2358. 
adolescencia hasta los 28, juventud hasta los 50, madurez o gravitas hasta los 70 y, finalmente, senectud o vejez, que por ser la última del ciclo vital no presentaba límites de edad ${ }^{89}$.

\section{VI.1. La primera infancia}

La dimensión pedagógica del infans o primera infancia la dividió en tres fases: antes del nacimiento, el periodo de lactancia y el comienzo del habla reflexiva. Sobre la primera, dirá que la esposa debía ser mujer joven, sana y fuerte para poder gestar, alumbrar y amamantar muchos hijos ${ }^{90}$. Preferible de la misma edad y estatura, «para que en la actuación conyugal el desajuste en estos puntos no malogre las energías del otro o incluso impida el fruto del matrimonio» ${ }^{91}$. La mejor edad para casarse es la de los 13-15 años para las mujeres y 16-18 para los hombres ${ }^{92}$. Para la procreación de los hijos aconseja como mejores épocas la primavera y el invierno, por aportar equilibrio y fortaleza al embrión, y desaconseja el verano y el otoño porque su calor extingue y acaba con los fluidos naturales del cuerpo $^{93}$; en esa línea, aconseja no hacer uso del matrimonio tras largos ayunos, esfuerzos físicos importantes y después de las comidas por «retraer al organismo su energía» y repercutir en un embrión débil ${ }^{94}$.

Tras el parto, en el que curiosamente aconseja la conveniencia de que el padre esté presente ${ }^{95}$, la lactancia y primera alimentación concitan todo el interés pedagógico. Como buen hipocrático, sostendrá que leche materna es el principio y la base de la vida ${ }^{96}$, representa el principio del carácter y linaje ${ }^{97}$. Cuando no pueda darse por la madre, deberá elegirse una nodriza óptima. Sera «de edad mediana, esto es, entre veinticinco y treinta años [...]. Se cuidará mucho su apariencia física, sus costumbres, la forma de sus senos, la calidad de su leche y el tiempo que haya pasado desde su último parto ${ }^{98}$. $«$ Una vez haya acabado la lactancia, al

\footnotetext{
89 Speculum doctrinale... [ver n. 8], lib. XII, cap. CLXXIII: De bomine et aetatibus hominis.

90 Speculum doctrinale... [ver n. 8], lib. XII, c. 29.

91 De eruditione... [ver n. 9], 47,7.1.

92 Speculum naturale... [ver n. 8], lib. XXXI, cap. 6, col. 2295-2296,

93 Speculum naturale... [ver n. 8], lib. XXXI, cap. 6, col. 2295

94 Speculum naturale... [ver n. 8], lib. XXXI, cap. 6, col. 2295-2296.

95 Speculum naturale... [ver n. 8], lib. XXXI, cap. 57, col. 2335-2336.

96 Speculum doctrinale... [ver n. 8], lib. XII, cap. 29, col 1091.

97 Speculum doctrinale... [ver n. 8], lib. XII, cap. 29, De eligenda nutrice et eius regimine.

98 Speculum doctrinale... [ver n. 8], lib. XII, cap. 29. [col 1091].
} 
niño se le tendrán que prohibir las comidas y los dulces en abundancia, y, de la misma manera, no podrá consumir productos harineos y grasos, ni podrá beber agua turbia, que predispone a cálculos. Tampoco se le habrá de acostumbrar al consumo de vino, porque le aumentará el calor y la humedad del cuerpo, propias de la complexión infantil. Solo se les podrá dar vino en cantidades módicas, para que les ayude a orinar, les reduzca la sensación de saciedad y les calme la sensación de sequedad que da el comer» ${ }^{99}$.

Cuando comience a balbucear sus primeras palabras, al finalizar el primer año de vida, es importante estimular su lenguaje sembrando equilibrio emocional y evitando sensaciones fuertes. Los cuentos y relatos de fantasías serán una más de las obligaciones de la madre, que propondrá largos sueños y evitará que el infante duerma a plena luz o con luces intensas; le mostrará colores vivos para despertar su sensibilidad y le cantará canciones suaves y bajas (Dulcibus cantilenis) ${ }^{100}$. En ese marco, el juego y la higiene son igualmente importantes. El día debía comenzar con un baño inmediatamente después de despertar; a continuación, recomienda una hora de juego antes del desayuno, jugar el resto de la mañana y bañarse antes de la comida ${ }^{101}$. Todo un programa pedagógico, pretendidamente científico, que debía garantizar el crecimiento natural y preparar para nuevas empresas pedagógicas.

\section{VI.2. La puericia}

El segundo estadio vital es la puericia. Término que etimológicamente significa ingenuidad, pureza, sencillez ${ }^{102}$. Se extiende desde el comienzo articulado del habla -cuatro cinco años- hasta los catorce años. Un tiempo ideal para que el alma, por disposición natural, empiece a pensarse a sí misma, a tomar conciencia de los primeros principios y sobre todo a sembrar y cultivar en ella hábitos pedagógicos de orden físico, moral, intelectual y trascendente ${ }^{103}$. Con Quintiliano, dirá: «el hombre debe ser educado sobre todo en esa edad que no sabe fingir y que se somete con mucha facilidad a sus preceptores» ${ }^{104}$.

\footnotetext{
99 Speculum doctrinale... [ver n. 8], lib. XII, cap. 31: De regimine puerorum.

100 Speculum naturale... [ver n. 8], lib. XXXI, cap. 60, col. 2338.

101 Speculum doctrinale... [ver n. 8], lib. XII, cap. 31:

102 Speculum naturale... [ver n. 8], lib. XXXI, cap. 80:

103 Speculum doctrinale... [ver n. 8], lib. XII, cap. 173.

104 Quintiliano, Institutio Oratoria, I. De eruditione... [ver n. 9], 1,6.3.
} 
El programa pedagógico de esta etapa lo cifró Vicente en cinco áreas: la conformación del carácter, la relación salud alimentación, el ejercicio físico moderado, el cultivo de virtudes religioso-morales y el inicio de la formación intelectual. La formación del carácter no dependía del temperamento o fondo endotímico de la persona, estaba más en relación con los hábitos, con la formación moral, con la disciplina o sujeción a norma:

En cuanto al cuidado de los niños -dirá Vicente- se ha de poner todo el empeño en el entrenamiento y perfeccionamiento de sus hábitos, esto es, que no experimenten sentimientos como la ira desmesurada, el miedo exagerado, la tristeza, o bien el insomnio. Las ventajas de dicho método son de dos tipos: por un lado, de orden moral, porque se aseguran, ya desde la niñez, la asimilación de los buenos hábitos y su constante práctica; por otro, de orden físico, puesto que los malos hábitos, una vez adquiridos, generan trastornos temperamentales. Por ejemplo, la ira calienta sobremanera, la tristeza provoca sequedad, la pereza da rienda suelta a los instintos más animalescos y predispone a un temperamento flemático. La salud del cuerpo y, al mismo tiempo, del alma consiste en la sobriedad moral ${ }^{105}$.

Tras los consejos sobre el carácter viene la dieta. Concepto amplio que en la cultura escolástica significaba el uso ordenado de las sex res non naturales: comida, bebida, higiene, ejercicio físico, hidrología, etc. Vicente, siguiendo a Rhazes, dirá:

En el caso de que un niño padeciera enfermedades, y sobre todo estreñimiento o diarrea, no se le ha de proporcionar medicación alguna, sino que se le ha de administrar semillas escarificadas y, respectivamente, jarabe de fruta con un alto contenido de agua. [...]. Sin embargo, que se les dé pepitas de melón con azúcar, porque su ingestión estimula el buen funcionamiento del aparato urinario y, por tanto, impide que se formen cálculos. Asimismo, que no se les permita comer hasta la saciedad ni que vuelvan a comer antes de que haya finalizado la digestión $^{106}$.

El tercero pilar pedagógico de la puericia era el ejercicio físico. Tema al que el naturalismo greco-árabe prestó atención considerable y que Vicente, quizás por su entorno religioso y monacal, apenas consideró. Se limitó a manifestar que no comenzase antes de los doce años, siendo especialmente indicado para niños llamados a ser arquitectos o albañiles ${ }^{107}$.

105 Speculum naturale... [ver n. 8], lib. XXXI, cap. 81, col. 2354:

106 Speculum doctrinale... [ver n. 8], lib. XII, cap. 31: De regimine puerorum.

107 Speculum doctrinale... [ver n. 8], lib. XII, cap. 31. 
No ocurre igual con la formación religioso-moral. Una recurrente y grave obligación de los padres que nuestro dominico motivará con la autoridad de las citas bíblicas. Con Efesios 6,4, sostendrá: «educadlos en la disciplina y en el respeto del Señor» ${ }^{108}$; con Tobías 1,9-10, recalcará: «enseñándoles desde su infancia a temer a Dios y a abstenerse de todo pecado» ${ }^{109}$; y con Proverbios, 19,17 , concluirá: «Forma a tu hijo y te refrescará y hará las delicias de tu alma» ${ }^{110}$. Argumentos que obedecían a razones prácticas de índole natural. Para nuestro polígrafo el alma del niño se presentaba como tabla rasa llamada a grabar de forma indeleble los primeros principios. Por eso, con el Pseudo-Varrón, sentenciará: «los vasos de arcilla saben al sabor de su primer contenido; lo mismo pasa con los niños» ${ }^{111}$. Y con el capítulo XXIV del De eruditione, cencluye: la religión y la moral, cultivadas desde la infancia, posibilitan una larga y fecunda convivencia con el bien, anclan al niño en la perfecta y duradera sabiduría ${ }^{112}$.

El último pilar que cierra el armazón pedagógico de la puericia lo conformaron pequeñas referencias al inicio progresivo de la formación intelectual. Un propósito, que quiso hacer efectivo no antes de los seis años, aunque expresamente matizó que no era necesario acudir diariamente a recibir lecciones ${ }^{113}$. A partir, sin embargo, de los doce años, con el despertar del pensamiento abstractivo, la formación debía adquirir rango de sistematicidad y orden.

\section{VI.3. La adolescencia}

La tercera edad de la vida, quizá la más problemática es la adolescencia. Una etapa que «empieza en el año décimo cuarto y llega hasta el trigésimo» ${ }^{114}$. Un momento en el que el puer abandona la niñez, la ingenuidad y el cuidado de la madre para pasar a una etapa vital problemática, bajo el cuidado atento del padre y mayores ${ }^{115}$. Etapa ante la que Vicente mantendrá especiales prevenciones. Con san Ambrosio, dirá: «la niñez tiene como característica propia la inocencia; la ancianidad, la prudencia; la madurez, la vergüenza de delinquir. Sólo la adolescencia

\footnotetext{
108 De eruditione... [ver n. 9], 23,4.

109 De eruditione... [ver n. 9], 23,4.1.

110 De eruditione... [ver n. 9], 23,5.0.

111 Pseudo-VArrón, Sententiae, 58a. De eruditione... [ver n. 9], 24, 99, 1.

112 De eruditione... [ver n. 9], 24,2.1.

113 Speculum doctrinale... [ver n. 8], lib. XII, cap. 31: De regimine puerorum.

114 Speculum doctrinale... [ver n. 8], lib. XII, cap. 173: De bomine et aetatibus bominis.

115 Speculum naturale... [ver n. 8], lib. XXXI, cap. 82, col. 2355.
} 
es débil de fuerzas, insegura en sus decisiones, ardiente con el vicio, fastidiosa a los preceptores, seductora con sus encantos» ${ }^{116}$.

Una visión no muy positiva que se abordaba con la ayuda de tres flancos: la salud corporal, la educación religioso-moral y la atención intelectual. En esta etapa, la salud o equilibrio humoral es de todo punto fundamental por las muchas imprudencias que en ella se cometen ${ }^{117}$. A tal efecto, dirá:

Es necesario que los adolescentes hagan un ejercicio moderado y habitual y que no se expongan mucho al calor del sol. Tienen que bañarse en un agua templada y en el verano en agua fría, dulce y suave. Por tanto, tienen que evitar los alimentos que producen calor porque dan origen a la cólera o bilis, entre otros cebollas, mostaza y similares. [...] Tomen alimentos fríos, como peces frescos, carnes de cabritos cocidas con condimentos fríos y acostúmbrese a los frutos como granadas, melocotones y otros así, puesto que su complexión es connatural con esos frutos. [...] Acostumbre los cuerpos a las sangrías y a los laxantes, sobre todo en primavera ${ }^{118}$.

En paralelo con la salud, debe cuidarse la dimensión religioso-moral. Pero si en la puericia se planteaba como siembra y preparación de futuros procesos pedagógicos, en la adolescencia se presenta como necesidad ineludible de una etapa marcada por su debilidad moral. Vicente planteó con énfasis la necesidad de esta recurrencia en los capítulos 35 y 36 del De eruditione, donde a los tres males que presidían la adolescencia: pusilanimidad, lujuria y lascivia ${ }^{119}$ se oponían la virtualidad de tres virtudes: la humildad, que vence a la animosidad ${ }^{120}$; el pudor, que se opone a la impureza ${ }^{121}$; y la templanza, que frena la lascivia ${ }^{122}$. Y todo ello acompañado de la fuerza insoslayable de la gracia conseguida por la virtualidad de los sacramentos ${ }^{123}$.

El último de los pilares que sostiene las posibilidades pedagógicas de la adolescencia se resume en el poder transformador de la formación intelectual. Vicente tiene el prurito del optimismo racionalista de su tiempo. Piensa que el conocimiento, al conocer la voluntad de Dios en la multiplicidad formal de la na-

\footnotetext{
116 Ambrosio, De interpellatione, I, 7, 21: PL 14, 806B (633). De eruditione... [ver n. 9], 36,1.1.

117 Speculum naturale... [ver n. 8], lib. XXXI, cap. 85: De incolumitate, col. 2358.

118 Speculum doctrinale... [ver n. 8], lib. XII, cap. 32: De regimine adolescentium.

119 De eruditione... [ver n. 9], 35,3-5.

120 De eruditione... [ver n. 9], 36,5-7.

121 De eruditione... [ver n. 9], 36,8-9.

122 De eruditione... [ver n. 9], 36,10-11.

123 Agustín, De Civitate Dei, XXI, 16: PL 41, 73. De eruditione... [ver n. 9], 35,5.2.
} 
turaleza, dirige la voluntad al bien por la fuerza de la disciplina y de la gracia. Un proceso, que, si es sincero, eleva al adolescente a emprender los grandes caminos que marcarán el sentido de su vida ${ }^{124}$.

\section{VI.4. La juventud}

Pasadas las dificultades y pesimismos de la adolescencia, Vicente nos adentra en la juventud. A diferencia de la anterior, es una etapa más positiva y gratificante, se extiende desde los treinta a los cincuenta años ${ }^{125}$, y define al hombre por su robustez, por sentir la vida como un continuo presente, como una actualidad constante y donde apenas había lugar a la precariedad o caducidad ${ }^{126}$. Sólo su proclividad a un patente impulso sexual, aunque más moderado que en la adolescencia, y la persistencia de vicios como la ira y la soberbia afeaban un presente de fuerza y plenitud física ${ }^{127}$.

Conservar esas esperanzas y dirigir a buen puerto sus posibilidades serán los propósitos de una etapa que nuestro polígrafo cifrará en dos frentes recurrentes: la reiterada conservación de la salud y la consolidación de la virtud moral. La salud tiene mucho que ver con la alimentación. «Los cuerpos en esta etapa han llegado a su término, aumentan en ellos los sobrantes y se precipitan sobre ellos las enfermedades a causa del hartazgo» ${ }^{128}$. Un mal con el que no hay que contemporizar, sino más bien atajar con el deseo firme de un peso equilibrado $^{129}$, mantenido con una dieta rica en verduras, carne y pescado ${ }^{130}$. De no conseguirlo, se adelgazará «soltando el vientre con purgas o laxantes» ${ }^{131}$. A todo ello «ayudará los masajes» ${ }^{132}$, «hacer un ejercicio moderado y habitual y no exponerse mucho al calor del sol» ${ }^{133}$, y mantener así el equilibrio de su complexión caliente y seca ${ }^{134}$.

124 Speculum doctrinale... [ver n. 8], lib. I, col. 2.

125 Speculum doctrinale... [ver n. 8], lib. XII, cap. 173.

126 Speculum doctrinale... [ver n. 8], lib. XII, cap. 32.

127 Speculum doctrinale... [ver n. 8], lib. XV, cap. 173.

128 Speculum naturale... [ver n. 8], lib. XXXI, cap. 83, col. 2356.

129 Speculum naturale... [ver n. 8], lib. XXXI, caps. 62-63, cols. 2339-2340.

130 Speculum naturale... [ver n. 8], lib. XXXI, cap. 64, col. 2340-2341.

131 Speculum doctrinale... [ver n. 8], lib. XII, cap. 32.

132 Speculum naturale... [ver n. 8], lib. XXXI, cap. 64-65. col. 2341.

133 Speculum naturale... [ver n. 8], lib. XXXI, cap. 83. col. 2356.

134 Speculum doctrinale... [ver n. 8], lib. XIII, cap. 14. 
Sobre la educación moral de esta etapa, Vicente no dice mucho. Mas que adquirir nuevas virtudes se trata de conservar y aumentar las ya adquiridas. En cualquier caso, insiste en dos actitudes: una, mirar al pasado para reflexionar sobre el tiempo perdido, nuestras miserias y debilidades, lo que debe llevarnos a pedir perdón a Dios y a darle las gracias por mantenernos en el ser ${ }^{135}$; la segunda actitud consiste en afirmar el presente, recreando nuestras fuerzas no en las cosas hechas, no en los beneficios conseguidos o en las temporalidades de la vida, sino en lo que falta por hacer, en lo que aún nos queda por conseguir ${ }^{136}$.

\section{VI.5. Madurez y vejez}

A partir de los 50 años puede decirse que ya ha terminado lo que las fuentes medievales denominaron pulchritudo, dando paso a las últimas etapas psicofísicas de la vida: la madurez y la vejez. Un periodo que puede considerarse más o menos uniforme, pero con matices diversos que llevaron a los escolásticos a distinguir en él dos momentos diferentes: un primero, entre los 50 y 70 años, que sería propiamente la madurez y al que denominaron gravitas, senectud, senes a senectute...; y un segundo, de los 70 años en adelante, que sería lo considerado propiamente ancianidad, $\mathrm{y}$ al que calificaron con las expresiones senes a senio, decrepita, etc.

Lo propio de estas edades era el descenso de la virilidad, de la fuerza, de la robustez, de las posibilidades físicas y psíquicas. Un descenso progresivo e inexorable, que demanda una atención especial de la salud ${ }^{137}$. «Puesto que la complexión de los viejos es caliente y húmeda -dice Vicente-, el anciano necesita regirse por un régimen cálido y húmedo. Debe habitar en un lugar en el que el aire no sea seco sino semejante al primaveral. Si su fuerza es débil, que vaya a caballo y disminuya el paseo. Quien sea más fuerte, que ande sin fatigarse. Báñese en agua dulce y caliente, y después de una hora descanse. A continuación, coma alimentos calientes y húmedos, digestibles y que desciendan pronto del estómago» ${ }^{138}$. Para después, prohibir expresamente el coito por las fuerzas que extrae ${ }^{139}$.

Vicente cierra estas etapas haciendo una invitación a la voluntad dócil y presta que, aun en el ocaso de la vida y en el arrope de una salud psicofísica de-

\footnotetext{
135 Bernardo, In Capite feiunii, sermo II, 4: PL 183, 173C (818). De eruditione... [ver n. 9], 40,3:

136 Gregorio Magno, Moralia, XXII, 5, 10; 6, 12: De eruditione... [ver n. 9], 40,15:

137 Speculum naturale... [ver n. 8], lib. XXXI, cap. 87: col. 2360.

138 Speculum naturale... [ver n. 8], lib. XXXI, cap. 89: De regimine illius aetatis, col. 2361-2362:

139 Speculum naturale... [ver n. 8], lib. XXXI, col. 2362.
} 
bilitada, decide seguir aprendiendo. Una actitud positiva y esperanzadora que reforzará con San Ambrosio, afirmando: «ninguna edad es tardía para aprender. No hay que alabar la blancura de los años sino de las costumbres» ${ }^{140}$; y con Séneca, concluirá: «Que la vejez se reproche a sí misma los años consumidos en vanos afanes. Hagamos lo que se suele hacer en los viajes: los que hemos salido más tarde démonos prisa acortando el retraso con mayor velocidad, y ocupémonos de la gran obra de la vida sin la excusa de la edad» ${ }^{141}$.

\section{INFLUENCIA Y PROYECCIÓN}

«Llegada ya a su fin, gracias a Dios, esta obra tan grande y laboriosa, también yo deseo conducir al puerto de su descanso a mi mente» ${ }^{142}$. Tras estas palabras sentidas, que Vicente escribió al finalizar su Speculum maius, cabe formularse la pregunta: cuál fue el alcance, significado y proyección de la obra bellovaca. Indudablemente no es fácil responder esta cuestión, la formación es una categoría inmanente que queda en el espíritu, en la interioridad del hombre y en el devenir de la cultura histórica. Aun así, podemos objetivar algunos datos significativos. Si nos atenemos a sus escritos enciclopédicos, conocemos 240 manuscritos del Speculum historiale, 50 del Speculum naturale y 20 del Speculum doctrinale. En 1624 se imprime la llamada edición duacense y en 1964 en Graz-Austria, la Akademische Druck-u Verlagsanstalt hace en cuatro tomos una edición fotomecánica de la edición de $1624^{143}$.

Más importante si cabe es la influencia del De eruditione filiorum nobilium, que puede catalogarse como el punto de ignición de la Pedagogía como ciencia. En la Edad Media tuvo una notable difusión, conservándose una treintena de manuscritos ${ }^{144}$. Influye en la primigenia pedagogía franciscana, los capítulos sobre el maestro y el discípulo del De modo addiscendi (c. 1262) de Gilbert de Tournai son copia literal del De eruditione bellovaco; lo mismo puede decirse del De eruditione principum (1272 c.) de Guillaume de Perrault, más de dos terceras partes de su obra se deben a la influencia de nuestro belvacense.

140 Speculum naturale... [ver n. 8], lib. XXXI, col. 2362.

141 Séneca, De naturalibus cuestionibus, lib. III, Praef., 2-4. De eruditione... [ver n. 9], 40,5.

142 Libellus apologeticus... [ver n. 13], cap. XVIII: Retractatio primae partis. cols. 14-15

143 T. KAEPPELI, Scriptores Ordinis Praedicatorum, vol. IV, Roma, 1993, pp. 454-455.

144 R. J. SCHNEIDER y H. VOORBIJ, A hand-list of manuscripts of the minor treatises of Vincent de Beauvais, en Vincent of Beauvais Newsletter, vol. XII, 1987, pp. 9-11. 
En el Renacimiento, el De eruditione fue un punto de obligada referencia pedagógica. Se tradujo en dos ocasiones al francés: una primera, en 1380, por Jean Daudin y, otra, por Jean Golein (1320-1403). Igualmente dejó huella en el De educatione liberorum de Mafeo Vegio. Y sus ideas están explícitas en La regola del goberno di cura famigliare, publicada en 1400 por el cardenal Giovanni Dominici, quien llamó a Vicente: «facundissimum fratrem Vincentium speculatorem», situándolo a la altura de Hugo de San Víctor, Tomás de Aquino y Alberto Magno. La parte cuarta de esta obra, dedicada a la educación de los hijos, copia citas literales de Vicente y presenta sus mismos principios y modelos. Reminiscencias belvacenses se encuentran también en el De liberorum educatione de Eneas Silvio Piccolomini, -futuro papa Pío II- quien, en sus consejos educativos al rey Ladislao de Hungría, repite citas y fuentes del De eruditione. Los tórculos de la imprenta también se hicieron eco de él al publicarse en dos ocasiones: primero en Rostock, 1477, en la imprenta de los hermanos Horti Viridis; y después en Basel, 1481, en la imprenta de Johannes von Amerbach.

Los siglos XVII y XVIII, por el empuje de la llamada nueva ciencia, condenaron su obra al ostracismo. En el siglo XIX, la pedagogía alemana reivindicó su interés hasta el punto de traducirse en dos ocasiones al alemán: una por Friedrich Christian Schlosser (1819) y otra por Augusto Millauer (1887). El siglo Xx le hará un hueco mayor: Arpard Steiner reeditará en 1938 una edición crítica del De eruditione $^{145}$ y en 1940, William Ellwood Craig brindará su primera traducción a lengua inglesa ${ }^{146}$. En el 2011, la Collectio scriptorum mediaevalium et renascentium hará la primera traducción a lengua castellana.

En todo este devenir hay una parte que no tuvo tanta proyección: su naturalismo pedagógico, que fue absorbido por los regimina sanitatis de entonces. Además, hubo hechos que llamaban a su prudencia. Un exponente lo constituye los Libri naturales aristotélicos, que presentaban posturas difíciles de conciliar con algunas verdades cristianas. Incluso, entre los propios Predicadores había sectores espiritualistas que renegaban del cultivo de las ciencias profanas. A tal extremo llegó su actitud que el capítulo general de 1228 prohibió el estudio de las ciencias naturales ${ }^{147}$. En el capítulo general de 1244 se volvió a renovar esta prescripción, decretándose, además, que todos los hermanos que cultivasen las nuevas

145 A. STEINER, Vincent of Beauvais: «De eruditione filiorum nobilium», The Mediaeval Academy of America, Cambridge, Massachusetts, 1938.

146 W. E. CRAIG, Vincent of Beauvais, On the Education of Noble Children. Translated from medieval latin with notes and historical introduction, University of California, Los Angeles, 1960.

147 Analecta Sacri Ordinis Fratrum Praedicatorum, Typis Vaticanis, Romae, 1893, II, p. 643. 
ciencias o tuviesen textos profanos los sometiesen a la consideración del prior. Una excepción importante se contemplaba en este capítulo: los superiores de la Orden y los capítulos provinciales tenían autoridad para permitir a miembros individuales estudiar y cultivar las ciencias profanas ${ }^{148}$. En la última edición del Speculum maius (1256/59), Vicente se planteó si realmente había merecido la pena tratar con tanta amplitud y extensión las ciencias profanas y concretamente todo lo relacionado con la filosofía natural. Dudaba si dichos saberes podían realmente contribuir a una mejor comprensión de las Sagradas Escrituras -fin primario y último de toda su obra-, o si por el contrario se quedaban en una mera y simple curiosidad intelectual ${ }^{149}$.

En cualquier caso y a título de conclusión general puede decirse que los primeros hijos espirituales de Domingo de Guzmán hicieron de su carisma fundacional una saber pedagógico de primer orden, dieron a la educación una sistemática científica desconocida hasta entonces e hicieron de puente entre la pedagogía clásica y la pedagogía del humanismo. El sillar y la base de todo ello fue la figura y la obra pedagógica de Vicente de Beauvais.

\section{REFERENCIAS BIBLIOGRÁFICAS}

\section{Fuentes impresas}

Vicente de Beauvais, El «Libellus apologeticus». Un símbolo del enciclopedismo medieval. (Estudio, traducción y notas por Javier VERGARA), Educación XX1, UNED, nº 6 (2003), pp. 149-202.

Vicente de Beauvais, Epístola consolatoria por la muerte de un amigo. (Estudio, traducción y notas Javier Vergara Ciordia, Francisco Calero Calero), Uned, baC, Madrid, 2006.

Vicente de Beauvais, De la formación moral del príncipe. (Estudio, traducción y notas por Carmen Teresa PABÓN DE ACUÑA, Edición bilingüe), UNED-BAC, Madrid, 2008.

Vicente de Beauvais, Speculum maius; naturale, doctrinale et historiale, Bibliotheca mundi. Ex officina Typographica Balthazaris Belleri in Circino aureo, Duaci, MDCXXIV.

Vicente de Beauvais, Tratado sobre la formación de los hijos de los nobles (1246). De eruditione filiorum nobilium. (Estudio, traducción y notas Ildefonso ADEVA y Javier VERGARA), UNED/BAC, Madrid, 2011.

148 Acta Capitalorum Provincialium Ordinis Fratrum Praedicatorum, 1239-1302, Imprenta y Librería Edouard Privat, Toulouse, 1894, pp. 486-488.

149 Libellus apologeticus... [ver n. 13], cap. XVIII: Retractatio primae partis, cols. 14-15. 
Vicentius Bellovacensis Opuscula. Scilicet: Libri de gratiae: Libri laudum Virginis gloriose: Liber de sancto fohanne evangelista: Liber de eruditione puerorum regalium: Liber consolatorius de morte amici. J. AMERBACH (ed.), Basel, 1481.

\section{Bibliografía}

ALBRECHT, E., The Organization of Vincent of Beauvais' Speculum Maius and of Some Other Latin Encyclopedias, 46-57 and 71-74 (Appendix A-B), en HARVEY, S. (ed.), The Medieval Hebrew Encyclopedias of Science and Philosophy: Proceedings of the Bar-Ilan University Conference. London 2000.

Albrecht, E., De ontstaansgeschiedenis en de compilatie van bet «Speculum Naturale» van Vincent van Beauvais († 1264). Ph.D., Katholieke Universiteit Leuven, Louvain 2007, 2 vols.

ATrio CEREzo, S., La matemática y su enseñanza en la Baja Edad Media. El Speculum doctrinale de Vicente de Beauvais, UNED, Madrid, 2006 (Tesis doctoral inédita, dirigida por J. VERGARA).

BATAILlON, J.L., L'activité intellectuelle des dominicains de la première génèration, en Lector et compilator, Vincent de Beauvais, frère prêcheur, un intellectuel et son milieu au XIII siècle. Grâne, Actes du Colloque de Royaumont, Editions Créaphis, 1997, pp. 9-21.

BOURNE, J.E., Educational Thought of Vincent of Beauvais, Universidad de Harvard, tesis doctoral inédita, 1960.

Brown, M.F., Contained Dissonance: The «Speculum maius» and Medieval Literary Practice, en Vincent of Beauvais Newsletter, 31 (2006), pp. 3-8.

Draelants, I. y PAUlmiER-FouCART, M., Échanges dans la societas des naturalistes au milieu du XIII siècle: Arnold de Saxe, Vincent de Beauvais et Albert le Grand, en Par les mots et les textes. Mélanges de langue, de littérature et d'histoire des sciences médiévales offerts à Claude Thomasset (Sorbonne), Paris, 2005, pp. 219-238.

FIJALKOWsKI, A., The Arabic Authors in the Works of Vincent of Beauvais, en Miscellanea Mediaevalia, 33 (2006), 483-495.

FIJALKOWSKI, A., The Education of Women in the Works of Vincent of Beauvais, en Miscellanea Mediaevalia. Veröffentlichungen des Thomas-Instituts der Universität zu Köln, vol. 27 (2000), 513-526.

FijalKOWSKI, A., The Estimation of the Value and Utility of the Intellectual Work in the 13th Century Europe on the Example of Vincent of Beauvais OP (1264) Works, en Studia Warminskie, 37/1 (2000), 27-47.

FIJALKOWsKi, A., Puer eruditus. Idee edukacyjne Wincentego z Beauvais (ok. 1194-1264) / Puer eruditus. The Educational Ideas of Vincent of Beauvais, Neriton Publishing House, Warszawa, 2001.

FIJALKOWSKI, A., Wincenty z Beauvais (ok. 1194-1264) w Royaumont Dominikanin Wsród Cystersów. Wyrwa, A.M. and J. Dobosz [eds], Cystersi w spoleczenstwie Europy Srodkowej, Poznan 2000, pp. 782-796. 
GABRIEL, A.L., The educational ideas of Vincent of Beauvais, Notre Dame (Ind.) 1956 (Texts and Studies in the History of Mediaeval Education 4). (Esta obra marcó en gran medida la historiografía pedagógica de nuestro dominico y en 1967 se tradujo al alemán: Vincenz von Beauvais, ein mittelalterlicher Erzieher, Neubearbeitete deutsche Ausgabe, Frankfurt/Main, 1967).

GRAGLIA, E., Il percorso dell'esistenza. Le età dell'uomo e i modelli educativi negli «Specula» di Vincenzo di Beauvais, M.A. thesis, University of Turin, 1996-1997.

Guzman, G.G., Vincent of Beauvais, en Glick, Th., Livesey, S.J., Wallis, F. [eds.], Medieval Science, Technology, and Medicine: An Encyclopedia, New York-London, 2005, pp. 501-502.

Hugo DE SAN VICTOR, Didascalicon de Studio Legendi (afán por el estudio). (Introducción, estudio preliminar, traducción y notas por Carmen MUÑOZ GAMERO y María Luisa ARRIBAS), BAC-UNED, Madrid, 2011.

LUSIGNAN Serge, Préface au Speculum maius de Vincent de Beauvais: réfraction et diffraction, Bellarmin, Montreal, 1979.

Lusignan, S., PAulmier-FouCART, M. [eds.], avec la collaboration de M.-C. Duchenne avec, Lector et compilator. Vincent de Beauvais, frère prêcheur. Un intellectuel et son milieu au XIII siècle, Rencontres à Royaumont, Editions Créaphis, Grâne (France), 1997.

MACCARTHY, J.M., Humanistic emphases in the educational thought of Vincent of Beauvais, E.J. Brill, Leiden, 1976.

NADEAU, A., Le statut des extraits du «De bomine» dans le «Speculum Naturale», de Vincent de Beauvais, en Cheneval, Fr., Imbach, R. \& Ricklin, Th. [eds.], Albert le Grand et sa réception au Moyen Âge. Hommage à Zénon Kaluza, Fribourg, 1998, 84-95.

NANU, Irina, [ed.], Vicente de Beauvais, «Tratado sobre la educación moral del príncipe. (De morali principis institutione)», en Memorabilia: boletín de literatura sapiencial, $\mathrm{n}^{\circ} 7$ (2003).

NANU, Irina, Aproximación al régimen «puerorum» en el «Speculum doctrinale» de Vicente de Beauvais y su posible relación con la Segunda Partida de Alfonso X el Sabio, en Memorabilia: boletín de literatura sapiencial, n. 9 (2006).

Palacios MARTíN, Bonifacio, Los dominicos y las órdenes mendicantes en el siglo XIII, en VI Semana de Estudios Medievales, Instituto de Estudios Riojanos, Logroño, 1996, pp. 29-41.

Paulmier-Foucart, M. y DuChenne, M. C., Vincent de Beauvais et le Grand miroir du monde, en Vincent of Beauvais Newsletter, 30 (2005), pp. 8-10.

Paulmier-Foucart, M., Le plan et l'évolution du «Speculum maius» de Vincent de Beauvais: de la version «bifaria» à la version «trifaria», en Meier, C. [ed.], Die Enzyklopädie im Wandel vom Hochmittelalter bis zur Früben Neuzeit, München, 2002, pp. 245-267.

PÉREZ MARTín, I., El «libro de Actor». Una traducción bizantina del «Speculum Doctrinale de Beauvais» (Vat. gr. 12 y 1144), en Revue d'Études Byzantines, 55 (1997), pp. 81-136 (4 facs.).

SCHNEIDER R. J. [ed.], Vincentii Belvacensis «De morali principis institutione», Turnhout, 1995 (Corpus Christianorum, Continuatio Mediaeualis 137). 
TArayre, M., La Vierge et le Miracle. Le Speculum Historiale de Vincent de Beauvais (Coll. Essais sur le Moyen Age, 22). (Éditions Honoré Champion), Paris, 1999.

TARAYre, M., Le sang dans le «Speculum maius» de Vincent de Beauvais. De la science aux miracula, en Le sang au Moyen-Age. $4^{e}$ Colloque du CRISIMA (Montpellier, 27-29 novembre 1997), Les Cabiers du Crisima, 4 (1999), pp. 343-359 (Publications de l'Université Paul Valéry, Montpellier III).

Vergara Ciordia, Javier, Enciclopedismo especular en la Baja Edad Media. La teoría pedagógica del espejo medieval, en Anuario de Historia de la Iglesia, vol. XVIII (2009), pp. 295-309.

Vergara CiORDia, Javier, La educación política en los tratados de príncipes medievales: el «Tractatus de morali principis institutione» de Vicente de Beauvais, en Homenaje al profesor Buenaventura Delgado, Universidad de Barcelona, Barcelona, 2009.

VERGARA CIORDIA, Javier, El aprendizaje en la Edad Media o la síntesis clásica de un pretomista: Vincente de Beauvais (1190-1264), en Laspalas Pérez, J. (ed.), Historia y Teoría de la Educación. Estudios en honor del profesor Emilio Redondo García, Pamplona, 1999, pp. 359-382.

VergaRA CIORDIA, Javier, El «Speculum doctrinale» de Vicente de Beauvais: un ideal prehumanista en la escolástica medieval, en García, G. [ed.], La idea de Europa en el siglo XVI, UNED-Aula Abierta, Madrid, 1999, pp. 73-107.

VERGARA CIORDIA, Javier, La educación politica en la Edad media: el «Tractatus de Morali principis institutione» de Vicente de Beauvais (1262/63). Una apuesta prehumanista de la política, EUNSA, Pamplona, 2010, p. 140.

Vergara CIORDIA, Javier, Vicente de Beauvais y el «Speculum maius, 1244-1259». Docencia e investigación. Homenaje al Profesor fosé Luis González-Simancas, EUNSA, Pamplona, 1998, 295-323.

VERGARA CIORDIA, Javier, El sentido del saber en la escolástica medieval, en Espacio, tiempo y forma. Serie III, Historia medieval, 13, (2000) 421-434.

VERGARA CIORDIA, Javier, Alcance y sentido de la cultura pedagógica bajomedieval, en Historia de la Educación, 24, (2005) 257-275. 
